\title{
Alterations in gene expression during sexual differentiation in androgen receptor knockout mice induced by environmental endocrine disruptors
}

\author{
DEHONG LIU ${ }^{1,2}$, LIPING SHEN ${ }^{1}$, YONGLIN TAO $^{3}$, YING KUANG $^{4}$, LEI CAI $^{4}$, DAN WANG $^{5}$, MEIDUO HE $^{3}$, \\ XUEBO TONG ${ }^{1}$, SHUGUANG ZHOU ${ }^{1}$, JIE SUN ${ }^{1}$, CHENCHEN SHI ${ }^{3}$, CHUNXIAO WANG $^{1}$ and YI WU $^{1}$ \\ ${ }^{1}$ Department of Pediatric Surgery, Ruijin Hospital, ${ }^{2}$ Department of Pediatric Surgery, Ruijin Hospital North, \\ ${ }^{3}$ Department of Pediatrics, Ruijin Hospital, Shanghai Jiaotong University School of Medicine, \\ Shanghai 200025; ${ }^{4}$ Shanghai Research Center for Model Organisms, Shanghai 201203; \\ ${ }^{5}$ School of Life Science, Shanghai University, Shanghai 200444, P.R. China
}

Received April 4, 2014; Accepted November 13, 2014

DOI: $10.3892 / \mathrm{ijmm} .2014 .2015$

\begin{abstract}
In the present study, we aimed to explore the effect of environmental endocrine disruptors (EEDs) on sexual differentiation in androgen receptor $(\mathrm{AR})^{-/-}, \mathrm{AR}^{+/-}$and $\mathrm{AR}^{+/+}$ male mice. By using a Cre-loxP conditional knockout strategy, we generated AR knockout mice. By mating flox-AR female mice with AR-Cre male mice, the offspring male mice which were produced were examined. Mice not subjected to any type of intervention were used as the controls. Furthermore, male mice of different genotypes were selected and further divided into subgroups as follows: the control group, bisphenol A (BPA) group and the D binding protein (DBP) group. The expression of the Wilms tumor 1 (WT1), lutropin/choriogonadotropin receptor (LHR), 17- $\beta$-hydroxysteroid dehydrogenase type 3 (17 $\beta$ HSD3) and steroid-5-alpha-reductase, alpha polypeptide 2 (SRD5A2) genes was determined by RT-qPCR and western blot analysis. There was no statistically significant difference in the weight of the mice between the control group and the knockout group $(\mathrm{P}>0.05)$. The results revealed that, compared with the control group, in the knockout group, anogenital distance was shortened, and testicular weight and testosterone levels were decreased; estradiol levels were elevated; the differences were statistically significant $(\mathrm{P}<0.05)$. In the group of $\mathrm{AR}^{+/}$male mice exposed to $100 \mathrm{mg} / \mathrm{l}$ EEDs, hypospadias was successfully induced, suggesting that EEDs are involved in the embryonic stage of sexual development in male mice. The quantitative detection of WT1, LHR, 17ßHSD3 and SRD5A2 gene expression by RT-qPCR and western blot analysis indicated that these genes were significantly downregulated in the mice in the BPA group. In conclusion, exposure to EEDs induces hypospadias in
\end{abstract}

Correspondence to: Dr Dehong Liu, Department of Pediatric Surgery, Ruijin Hospital, Shanghai Jiaotong University School of Medicine, 197 Ruijin Er Road, Shanghai 200025, P.R. China E-mail: dehongll1@gmail.com

Key words: environmental endocrine disruptors, hypospadias, sexual differentiation, transgenic mouse model heterozygous and wild-type male mice offspring during sexual differentiation, but has no effect on homozygous offspring. Therefore, EEDs play an important role during the third stage of sexual differentiation.

\section{Introduction}

Endocrine disruption has become a critical issue in environmental science, particularly after the endocrine-disrupting chemical pollution accident in Taiwan which attracted public attention worldwide (1). Consequently, over the last few years, multi-disciplinary research programmes regarding this issue have been conducted in several countries. Several environmental chemicals with anti-androgenic activities that have the potential to disrupt normal male sexual differentiation in utero have recently been identified (2,3). The detection of chemicals with the potential to disrupt normal androgen function is critical for the protection of human and ecological health.

The androgen receptor (AR), a member of the nuclear receptor superfamily, is composed of 919 amino acids (4). It contains an N-terminal transactivation domain, a central DNA-binding domain and a C-terminal ligand-binding domain (5). AR may form a dimer and interact with many co-regulators to modulate androgen target genes (6). Previous studies have demonstrated that AR is involved in a series of developmental and physiological functions, particularly in male sexual differentiation (7), the maintenance of adolescent sexual maturation (8), sperm production (9) and male sex hormone regulation (10). The function of androgens is mediated by the AR (11). Research has indicated that, during the process of sexual development, the number and activity of ARs has direct effects on target organs, and thus plays a crucial role in the onset of hypospadias (12). Male sexual differentiation is the result of complex mechanisms involving developmental genetics and endocrinology. Hormone function is mediated through specific receptors, functioning as transcriptional regulators. The disruption of these genetic events leads to abnormal sexual dimorphism involving both external and internal genitalia, and may also interfere with the development of other organs (13). 
Table I. Primers used for the construction of target vectors, Amhr2-Cre.

\begin{tabular}{ll}
\hline Primer & \multicolumn{1}{c}{ Sequence } \\
\hline Primer 1 & Forward: 5'-AAAAGGACATTAAGACCACATAAT-3' \\
& Reverse: 5'-GAAGCAGTGTCCAAAGCCCCATG-3' \\
Primer 2 & Forward: 5'-CTCCAAGCTTCCTCTGCCTCTTGAGT-3' \\
& Reverse: 5'-TGTACGGTCAGTAAATTGGACATAAACCAGCAAAAACCAG-3' \\
Primer 3 & Forward: 5'-CTGGTTTTTGCTGGTTTATGTCCAATTTACTGACCGTACA-3' \\
& Reverse: 5'-AATCTCTAGACTAATCGCCATCTTCCAGCA-3' \\
Primer 4 & Forward: 5'-TACGACGCGTGCATCTGCCACTGTGCCTGG-3' \\
& Reverse: 5'-CAGCCCGGACCGACGATGAA-3' \\
\hline
\end{tabular}

Transgenic and knockout mice have long been used as animal models to study the function of genes in vivo. Testicular feminization in male mice and androgen insensitivity syndrome in human male patients are the common models used for the study of the loss of androgen function (14). To generate tissue-specific AR knockout (ARKO) mice or female ARKO mice, a Cre-loxP strategy for conditional knockout is required. The Cre-loxP system utilizes the expression of P1 phage cre recombinase (Cre) to catalyze the expression of DNA located between flanking loxP sites (15). This strategy differs from the standard targeted gene disruption procedure in that the embryonic stem (ES) cells are generated in which the targeted segment is not disrupted but flanked by loxP sites (floxed). Thus, the target gene functions normally and mice can be bred which are homozygous at the targeted locus.

In the present study, we describe the generation and characterization of ARKO mice. The potential in vivo application of this mouse model for the study of the effects of environmental endocrine disruptors (EEDs) on sexual differentiation in $\mathrm{AR}^{-/}, \mathrm{AR}^{+/}$and $\mathrm{AR}^{+/+}$male mice is also discussed. We aimed to examine the role of EDDs in the third stage of sexual differentiation through the regulation of the expression of Wilms tumor 1 (WT1), lutropin/choriogonadotropin receptor (LHR), 17- $\beta$-hydroxysteroid dehydrogenase type 3 (17ßHSD3) and steroid-5-alpha-reductase, alpha polypeptide 2 (SRD5A2) genes in $\mathrm{AR}^{-/}, \mathrm{AR}^{+/-}$and $\mathrm{AR}^{+/+}$male mice. The results of the present study may provide a theoretical basis for the development of future preventive strategies to reduce EED contact.

\section{Materials and methods}

All experiments were approved by the Ruijin Hospital Ethics Committee and were performed in accordance with ethical standards.

Materials. C57BL/6 mice, 35-40 days old, weighing 18-22 g, were supplied by the Shanghai SLAC Laboratory Animal Co., Ltd. (Shanghai, China). The mice were raised in an air-conditioned room under controlled lighting and were fed standard laboratory chow and water ad libitum. DNA polymerase was purchased from Toyobo Co. (Osaka, Japan), proteinase K was from Merck (Billerica, MA, USA) and kits for the detection of testosterone and estradiol were purchased from Amersham Biosciences Corp. (Piscataway, NJ, USA). Immunohistochemical staining kits were purchased from CapitalBio Corp. (Beijing, China) and bisphenol A (BPA) and D binding protein (DBP) were obtained from Sigma-Aldrich (St. Louis, MO, USA). Antibodies to LHR, 17ßHSD3 and SRD5A2 were from Santa Cruz Biotechnology, Inc. (Santa Cruz, CA, USA).

Construction of targeting vector Amhr2-Cre. We designed the PCR primer 1 according to the Amhr2 promoter sequence previously reported (16). Genomic DNA from blood collected from the C57BL/6 mice was isolated as a template for PCR amplification. The amplified fragment has an expected size of $5 \mathrm{~kb}$ and was subcloned to the pMD18-T plasmid, and named Amhr5K-P-TV for further sequencing. The universal primer 2 was used to perform the amplification of bands of approximately $1 \mathrm{~kb}$ from Amhr5K-P-TV, and universal primer 3 was used to yield amplification bands of Cre approximately1 $\mathrm{kb}$ from the plasmid Aluminum-cre; both fragments were recycled. Recycling DNA was used as a template, and the reverse sequence of primer 2 and the forward sequence of primer 3 were used to perform the amplification of the $2 \mathrm{~kb}$ strip. The recycled $2 \mathrm{~kb}$ strip was digested with the HindIII and $\mathrm{XbaI}$ enzymes, and ligated with the pGL3-Basic plasmid digested with the same enzymes for further transfection. The identification of positive clones was carried out by PCR and the clone was named Amhr-1k CRE4. A fragment of $3 \mathrm{~kb}$ was amplified from plasmid Amhr5K-P-TV with primer 4, digested with the MluI and EcoRI enzymes and subcloned into the Amhr-1k-CRE4 clone (primer information is presented in Table I). Identification of positive clones was carried out by PCR and the clone was named Amhr-4k-CRE6 (8.2 KB). Following digestion with the EcoR, BamHI, EcoRV and ScaI enzymes, a promoter of $7.1 \mathrm{~Kb}$ was obtained which was connected to plasmid pRCH. The identification of the plasmid containing leydig cells expressing Cre recombinant enzyme and the specificity of the genetically modified (gm) sequence [Amhr2-Cre (7.1)] are shown in Fig. 1.

The microinjection of fertilized eggs. With the use of KpnI and $S a c I$ double enzyme digestion to construct the transgenic plasmid, the injection fragments were recycled. According to the conventional method, we performed microinjection and transplantation of the fertilized eggs.

Genotypic identification of geneticallymodifiedmice. Genomic DNA was extracted from the gonadal tissue of mice for PCR 


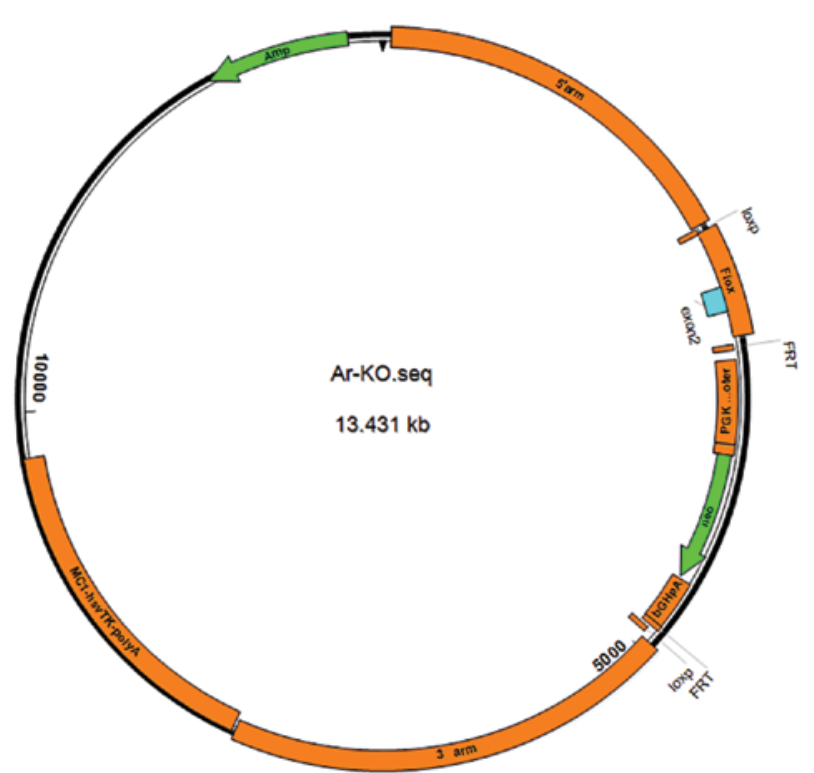

Figure 1. Plasmid for conditional androgen receptor (AR) gene knockout.

analysis. According to the gene sequence upstream and downstream of the Cre enzyme gene, we designed a pair of primers (primer 5: forward, TCTGTAGACTCTAGGCAGTTCCTGT and reverse, CAGCCCGGACCGACGATGAA). We employed this primer set to propagate the Cre enzyme gene of approximately $2,115 \mathrm{bp}$. The PCR reaction conditions were as follows: $95^{\circ} \mathrm{C}$ for $3 \mathrm{~min}$; followed by 26 cycles of $95^{\circ} \mathrm{C}$ for $15 \mathrm{sec}$ (denaturation) and $58^{\circ} \mathrm{C}$ (annealing temperature), $72^{\circ} \mathrm{C}$ for $2 \mathrm{~min}$ (elongation) and $72^{\circ} \mathrm{C}$ for $10 \mathrm{~min}$.

Heterozygous female mice mating with Amhr2-Cre transgenic mice, the experimental groups and exposure to EEDs. Heterozygous female mice mated with Amhr2-Cre transgenic mice bred heterozygous mice of the F1 generation. The $\mathrm{F} 1$ generation was then backcrossed to C57BL/6 mice for 2 generations, which then produced pure strains of heterozygous mice. F1 generation transgenic mice were selfed, producing homozygous mice with a clear genetic background. Heterozygous female mice were mated with homozygous male mice and became pregnant. The mice were divided into the following groups: the control group (no intervention), the BPA group (100 mg/l/day, by gavage) and the DBP group (100 mg/kg/day, by gavage). The pregnant heterozygous female mice were exposed to EEDs (mice were administered either DBP at $100 \mathrm{mg} / \mathrm{kg} / \mathrm{day}$ or BPA at $100 \mathrm{mg} / \mathrm{l} / \mathrm{day}$ ).

Reverse transcription-quantitative (real-time) PCR (RT-qPCR). Total cellular RNA was prepared using TRIzol reagent (Invitrogen Life Technologies, Carlsbad, CA, USA) and the expression levels of WT1, LHR, 17ßHSD3 and SRD5A2 were determined by real-time PCR using SYBR-Green. The data were normalized to GAPDH expression and represent the average of 3 independent experiments. The primer sequences were as follows: WT1 forward, 5'-CAAATGACATCCCAGCTTGA-3' and reverse 5'-GACACCGTGCGTGTGTATTC-3'; LHR forward, 5'-ATATTCAAGAGATGCACTGTGCAG-3' and reverse, 5'-AAGCAGAGTGTCAATGGGAAATAG-3'.

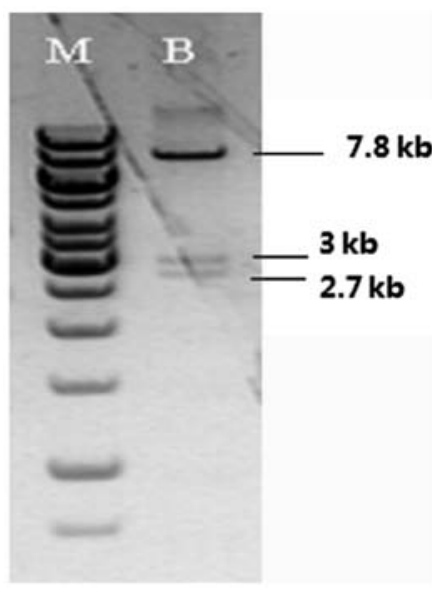

Figure 2. Androgen receptor (AR) gene condition knockout plasmid was identified and confirmed by enzyme digestion with BamHI.

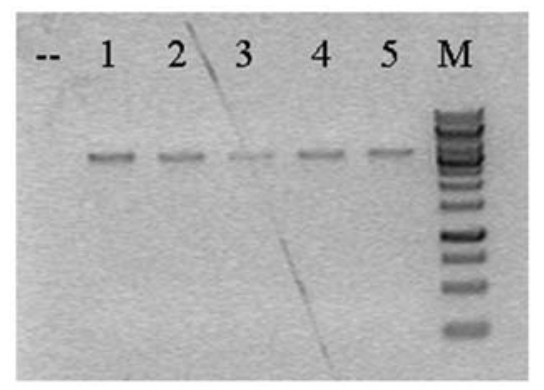

Figure 3. The PCR production of genome DNA of drug-resistant ES cell clones. Lanes 1-5, 5' arm PCR; --, 5' arm negative control; M, MBI GeneRuler 1 kb DNA Ladder Ferments.

Western blot analysis. Western blot analysis was performed as previously described (17). Cell lysates were subjected to SDS-polyacrylamide gel electrophoresis and immunoblot analysis with antibodies to WT1, LHR, 17 $\beta$ HSD3 and SRD5A2 (all from Santa Cruz Biotechnology). Radioiodinated Staphylococcus protein A (IPA) was used as the antibody and $\beta$-actin was used as a control for normalization.

\section{Results}

Construction of transgenic mouse model (Amhr2-Cre). The AR gene condition knockout plasmid was identified and confirmed by enzyme digestion with BamHI. Fig. 2 illustrates that 3 fragments with a size of $2.7,3$ and $2.7 \mathrm{~kb}$ were visible by agarose gel electrophoresis.

Breeding of chimeric mice. A total of 96 drug-resistant ES cell clones was identified by PCR; homologous recombination arms occurred in 5 ES clones (Fig. 3). PCR products confirmed by DNA sequencing further pointed out that there were only 2 positive clones, and these 2 positive ES clone blastocysts were injected and implanted in the uterus of pseudo-pregnant mice. The mice with a chimeric rate $>50 \%$ were mated with C57BL/6 mice; thus, 6 F1 generation female mice with 2 'positive arms' were produced. 
Table II. Comparison of anogenital distance, testicular weight, blood testosterone levels and estradiol concentration between the 2 groups.

\begin{tabular}{lcc}
\hline Index & $\begin{array}{c}\text { Control } \\
\text { group }\end{array}$ & $\begin{array}{c}\text { Knockout } \\
\text { group }\end{array}$ \\
\hline Weight $(\mathrm{g})$ & $22.3 \pm 2.1$ & $21.2 \pm 1.3$ \\
Anogenital distance $(\mathrm{cm})$ & $1.2 \pm 0.1$ & $0.5 \pm 0.1$ \\
Testicular weight $(\mathrm{g})$ & $0.087 \pm 0.002$ & $0.005 \pm 0.001$ \\
Blood testosterone $(\mathrm{nmol} / \mathrm{l})$ & $0.87 \pm 0.533$ & $0.054 \pm 0.043$ \\
Estradiol concentration $(\mathrm{nmol} / \mathrm{l})$ & $796 \pm 130$ & $1386 \pm 280$ \\
\hline
\end{tabular}

Data are presented as the means $\pm \mathrm{SD}$.

Table III. Incidence of hypospadias in $\mathrm{AR}^{+/}$and $\mathrm{AR}^{-/-}$male mice exposed to EEDs.

\begin{tabular}{lcc}
\hline $\begin{array}{l}\text { Exposure } \\
\text { to EEDs }\end{array}$ & $\begin{array}{c}\mathrm{AR}^{+/-} \text {male mice/ } \\
\text { cases of hypospadias }\end{array}$ & $\begin{array}{c}\mathrm{AR}^{-/} \text {male mice/ } \\
\text { cases of hypospadias }\end{array}$ \\
\hline BPA group & $32 / 30$ & $31 / 0$ \\
DBP group & $29 / 26$ & $33 / 0$ \\
\hline
\end{tabular}

EEDs, environmental endocrine disruptors; BPA, bisphenol A; DBP, $\mathrm{D}$ binding protein.

Comparison between $A R^{-/-}$male mice and normal mice. Maldevelopment, i.e. enlargement of the prostate, the seminal vesicles, the epididymis and the sponge balls was observed in the knockout mice. By contrast, in the control group, the prostate, the seminal vesicles, the epididymis and the ball sponges were normally developed. Comparisons regarding the anogenital distance, testicular weight, blood testosterone and estradiol concentrations were made between the control group and the knockout group as shown in Table II. There was no statistically significant difference in weight between these 2 groups $(\mathrm{P}>0.05)$. Compared with the control group, in the knockout group, the anogenital distance was significantly shortened, the testicular weight was significantly reduced, the testosterone levels were decreased and the estradiol levels were elevated; the differences were statistically significant $(\mathrm{P}<0.05)$.

Heterozygoous mice mated with Amhr2-Cre transgenic mice, the experimental groups and exposure to EEDs. In the group of $\mathrm{AR}^{+/}$male mice administered BPA (100 mg/l/day, by gavage) and DBP (100 mg/kg/day, by gavage) hypospadias was successfully induced, while the $\mathrm{AR}^{-/-}$mice did not have hypospadias. The detailed information is presented in Table III.

Disorders of sexual development in male mice following exposure to EEDs. The 10-week-old offspring mice were euthanized by anesthesia (in mice, testicular descent into the scrotum occurs at 45-55 days, sexual maturity is reached in approximatley 70 days). Secondary sexual differentiation, cryptorchidism, genital malformation, testicular atrophy, hyperplasia of supporting cells and fibrous tissue hyperplasia were observed in the male heterozygous mice exposed to EEDs (Fig. 4). These results suggest that EEDs are involved in the embryonic stage of the sexual development of male mice and contribute to the occurrence of disorders of sexual developmental during the embryonic stage.

Exposure to EEDs downregulates gene expression in mice. Testicular tissue-specific expression was analyzed by RT-qPCR. The quantitative detection of WT1, LHR, 17ßHSD3 and SRD5A2 gene expression in the mice exposed to EEDs (BPA and DBP) demonstrated that the expression of the aforementioned 4 genes was lower than that observed in the control group (non-exposed mice). The mRNA expression levels of WT1, LHR, 17ßHSD3 and SRD5A2 in testicular tissue were the lowest in the BPA group and the highest in the control group (Fig. 5). These results suggest that EEDs are involved in the embryonic stage of the sexual development of male mice and contribute to the occurrence of disorders of sexual development. Western blot analysis was used for the detection of the protein expression of WT1, LHR, 17ßHSD3 and SRD5A2 in testicular tissue. The results revealed that in the $\mathrm{BPA}$ and DBP groups, the expression levels of of the aforementioned 4 genes were lower than those in the control group. The protein expression levels of WT1, LHR, 17ßHSD3 and SRD5A2 in testicular tissue were the lowest in the BPA group and the highest in the control group (Fig. 6).

\section{Discussion}

In recent years, the incidence of hypospadias has been gradually increasing. A great amount of research on a wide range of aspects, from the epidemiological to the genetic aspects of hypospadias, has been carried out $(18,19)$. However, no consensus has yet been reached on this issue. Previous studies have suggested that the understanding of the normal development of the male external urethral orifice is an important step towards the understanding of the development of hypospadias $(20,21)$. Research focusing on the normal embryonic development of the penile urethra has formed a basis for understanding the development and pathogenesis of hypospadias $(22,23)$. By comparing the development of the urethra between humans and mice, scientists have found that the growth and development of the urethra are very similar between the two species during urethral seam formation (24). However, further studies are required to determine the association between AR expression and androgen signaling in males.

An increase in the incidence of hypospadias was reported in 1975 by the then newly established Norwegian Birth Defects Monitoring System (25). While the number of cases in that study was small (25), a continuation of this initial increase was subsequently reported by another study (26). Czeizel examined the rates of isolated hypospadia cases in Hungary between 1971 and 1983 and found that the incidence had increased significantly during this time period $(\mathrm{P}<0.01)(27)$. Matlai and Beral (28) examined the rates of malformations reported at birth and found a significant increase in cases of cryptorchidism, hypospadias and hydrocele between 1969 and 1983 in England and Wales (all P-values <0.001). Owing to the aggravating environmental pollution, the issue of developmental deformities has attracted public attention. However, the damage or defects that EEDs cause to the male reproductive system require further investigation. A number of scholars 


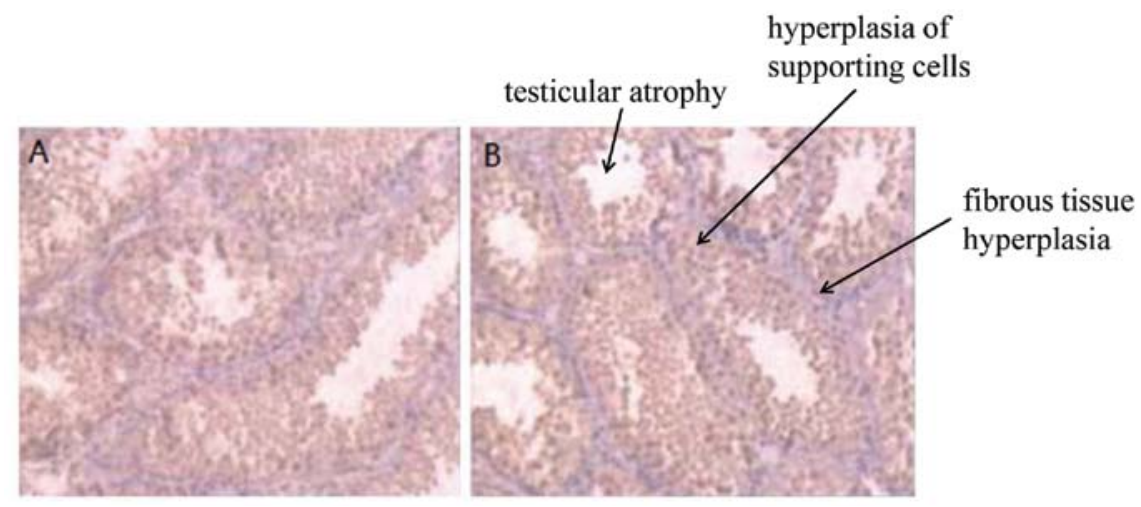

Figure 4. Disorders of sexual developmental in male mice following exposure to environmental endocrine disruptors (EEDs) indicated by H\&E staining. (A) Testicular tissue of the control male mice; (B) Testicular tissue of the male mice exposed to EEDs.

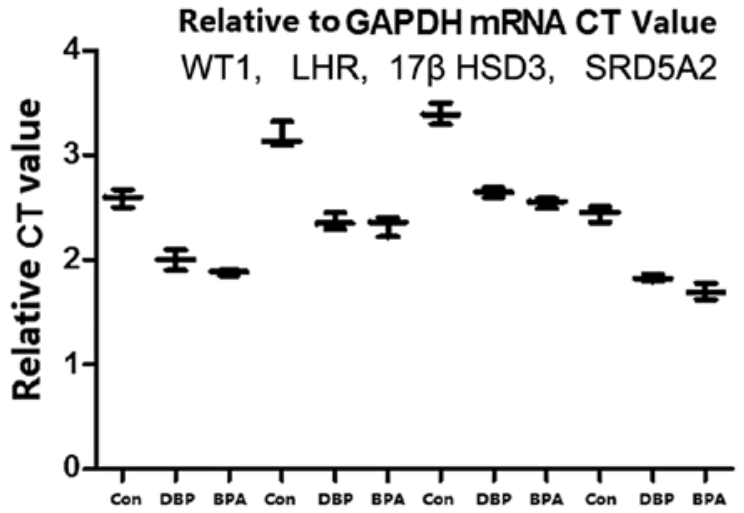

Figure 5. Quantitative detection of WT1, LHR, 17ßHSD3 and SRD5A2 mRNA expression in mice exposed to environmental endocrine disruptors (EEDs) compared with the control group (no exposure EEDs) RT-qPCR.

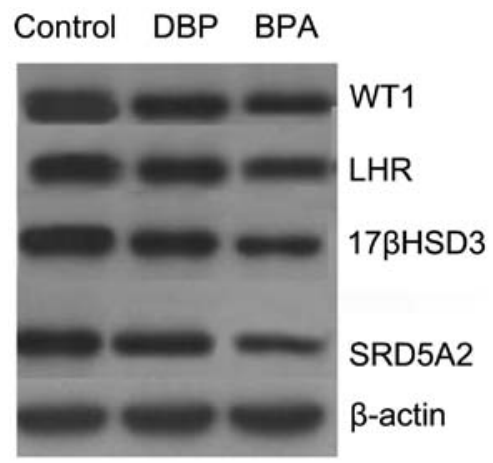

Figure 6. Quantitative detection of WT1, LHR, 17ßHSD3 and SRD5A2 protein expression in mice exposed to environmental endocrine disruptors (EEDs) compared with the control group (no exposure to EEDs) by western blot analysis.

believe that the incidence of hypospadias in recent decades in males is strongly associated with the significant increase in exposure to EEDs, such as BPA and DBP, which exist in high levels in the environment $(29,30)$. Existing research indicates that the male reproductive system is the target organ of EEDs, and that exposure to EEDs may result in significantly lower testosterone levels and can cause hypospadias, cryptorchidism, dysplasia of the epididymis and other male urogenital disorders (31).
Exposure to EEDs during the third stage of sexual development negatively affects the expression of genes related to male sexual development, such as WT1, LHR, 17/3HSD3 and SRD5A2 at the transcriptional and translational level. The transcription factors, SF-1 and WT1, play a pivotal role in mammalian gonadal development and sexual differentiation. In human embryos, both SF-1 and WT1 are expressed when the gonadal ridge first forms at 32 days post-ovulation (32). As the sex cords develop, providing morphological evidence of testis differentiation, SF-1 localizes predominantly to developing Sertoli cells in the sex cords, whereas WT1 retains a broader pattern of expression (33). At later stages, SF-1 predominantly localizes to steroidogenic Leydig cells, and WT1 localizes to the sex cords (33). In the ovaries, SF-1 and WT1 transcripts persist in the gonadal ridge from the earliest developmental stages throughout the critical period of sex determination (33). Human male sexual development is regulated by chorionic gonadotropin and luteinizing hormone. The aberrant sexual development caused by both activating and inactivating mutations of human luteinizing hormone receptor (LHR) has been described. Constitutive activity of the LHR causes LH releasing hormone-independent precocious puberty in boys and the autosomal dominant disorder, familial male-limited precocious puberty (34). The $17 \beta \mathrm{HSD} 3$ gene on chromosome 9q22 contains 11 exons. Defects in the conversion of androstenedione to testosterone in the fetal testes by the enzyme, 17beta-hydroxysteroid dehydrogenase (17ß-HSD), give rise to instances of individuals having female external genitalia despite being genetically male (35). Androgen production increases to normal progressively, so that testosterone and dihydrotestosterone concentrations are sufficiently high to gradually induce somatic and genital civilization, thus enabling an adequate male gender function (36). Prospective studies have suggested that the risk of developing prostate cancer may be increased in association with high serum concentrations of free testosterone and androstanediol glucuronide (Adiol G) (37,38). Polymorphisms have been identified in the 17-hydroxylase cytochrome P450 gene (CYP17) and SRD5A2, two genes that are involved in the biosynthesis and metabolism of androgens in males (39).

In conclusion, we successfully developed Amhr2-Cre genetically modified mice. Recombination between the LoxP loci in the genome for the application of the Cre-LoxP system was used to generate the knockout mice. Gene expression in testicular tissue was examined to determine its association with the development 
of hypospadias, cryptorchidism, small penis and testicles and other pediatric urological disorders. Our data indicate that the Cre recombinase is expressed in testicular tissue in Amhr2-Cre transgenic mice. These mice may serve as a useful tool for generating testis-specific gene knockout mice. The role of Cre recombinase in the development of disorders of the reproductive system may provide the ideal genetic tools for future research.

\section{Acknowledgements}

The present study was supported in part by grants from the National Natural Science Foundation of China (30700830), the Shanghai Hospital Science and Technology Resource Sharing Program Funded by the Shanghai Shenkang Hospital Development Center (SHDC12007708) and the Science and Technology Fund of Shanghai JiaoTong University School of Medicine (grant no. 06XJ21022). We thank the Shanghai Institute of Biochemistry and Cell Biology (SIBCB), the Shanghai Institutes for Biological Sciences (SIBS), the Chinese Academy of Sciences (CAS) and the Shanghai Research Center For Model Organisms. We are grateful to Yuan-Chang Yan, Yunbin Zhang, Jinjin Wang, Weijue Xu and Su Yan for their assistance in biochemical analysis and the animal experiments.

\section{References}

1. Yang J, Hauser R and Goldman RH: Taiwan food scandal: the illegal use of phthalates as a clouding agent and their contribution to maternal exposure. Food Chem Toxicol 58: 362-368, 2013.

2. Li X, Ye L, Wang X, et al: In silico investigations of anti-androgen activity of polychlorinated biphenyls. Chemosphere 92: 795-802, 2013.

3. Pan C, Wang Q, Liu YP, et al: Anti-androgen effects of the pyrethroid pesticide cypermethrin on interactions of androgen receptor with corepressors. Toxicology 311: 178-183, 2013.

4. Steketee K, Timmerman L, Ziel-van der Made AC, Doesburg P, Brinkmann $\mathrm{AO}$ and Trapman J: Broadened ligand responsiveness of androgen receptor mutants obtained by random amino acid substitution of $\mathrm{H} 874$ and mutation hot spot T877 in prostate cancer. Int J Cancer 100: 309-317, 2002.

5. Jenster G, van der Korput HA, Trapman J and Brinkmann AO: Identification of two transcription activation units in the $\mathrm{N}$-terminal domain of the human androgen receptor. J Biol Chem 270: 7341-7346, 1995 .

6. Li J and Al-Azzawi F: Mechanism of androgen receptor action. Maturitas 63: 142-148, 2009.

7. Bao AM and Swaab DF: Sexual differentiation of the human brain: relation to gender identity, sexual orientation and neuropsychiatric disorders. Front Neuroendocrinol 32: 214-226, 2011.

8. Raznahan A, Lee Y, Stidd R, et al: Longitudinally mapping the influence of sex and androgen signaling on the dynamics of human cortical maturation in adolescence. Proc Natl Acad Sci USA 107: 16988-16993, 2010.

9. Lazaros L, Xita N, Takenaka A, Sofikitis N, Makrydimas G, Stefos T, Kosmas I, Zikopoulos K, Hatzi E, Georgiou I: Semen quality is influenced by androgen receptor and aromatase gene synergism. Hum Reprod 27: 3385-3392, 2012.

10. Sarachana T, Xu M, Wu RC and Hu VW: Sex hormones in autism: androgens and estrogens differentially and reciprocally regulate RORA, a novel candidate gene for autism. PloS One 6: e17116, 2011.

11. Heinlein CA and Chang C: Androgen receptor (AR) coregulators: an overview. Endocr Rev 23: 175-200, 2002.

12. Wilhelm D and Koopman P: The makings of maleness: towards an integrated view of male sexual development. Nat Rev Genet 7: 620-631, 2006

13. Hiort $\mathrm{O}$ and Holterhus PM: The molecular basis of male sexual differentiation. Eur J Endocrinol 142: 101-110, 2000.

14. Yeh S, Tsai MY, Xu Q, et al: Generation and characterization of androgen receptor knockout (ARKO) mice: an in vivo model for the study of androgen functions in selective tissues. Proc Natl Acad Sci USA 99: 13498-13503, 2002.
15. Holt CL and May GS: A novel phage $\lambda$ replacement Cre-lox vector that has automatic subcloning capabilities. Gene 133: 95-97, 1993.

16. Teixeira J, Kehas DJ, Antun R and Donahoe PK: Transcriptional regulation of the rat Müllerian inhibiting substance type II receptor in rodent Leydig cells. Proc Natl Acad Sci USA 96: 13831-13838, 1999.

17. Burnette WN: 'Western blotting': electrophoretic transfer of proteins from sodium dodecyl sulfate-polyacrylamide gels to unmodified nitrocellulose and radiographic detection with antibody and radioiodinated protein A. Anal Biochem 112: 195-203, 1981.

18. Carmichael SL, Shaw GM, Nelson, V Selvin S, Torfs CP and Curry CJ: Hypospadias in California: trends and descriptive epidemiology. Epidemiology 14: 701-706, 2003.

19. Kalfa N, Philibert P and Sultan C: Is hypospadias a genetic, endocrine or environmental disease, or still an unexplained malformation? Int J Androl 32: 187-197, 2009

20. Rey RA and Grinspon RP: Normal male sexual differentiation and aetiology of disorders of sex development. Best Pract Res Clin Endocrinol Metab 25: 221-238, 2011.

21. Ching ST, Cunha GR, Baskin LS, Basson MA and Klein OD: Coordinated activity of Spryl and Spry2 is required for normal development of the external genitalia. Dev Biol 386: 1-11, 2014.

22. Qiao L, Tasian GE, Zhang H, et al: Androgen receptor is overexpressed in boys with severe hypospadias, and ZEB1 regulates androgen receptor expression in human foreskin cells. Pediatr Res 71: 393-398, 2012.

23. Vottero A, Minari R, Viani I, et al: Evidence for epigenetic abnormalities of the androgen receptor gene in foreskin from children with hypospadias. J Clin Endocrinol Metab 96: E1953-E1962, 2011.

24. Bhoj EJ, Ramos P, Baker LA, et al: Human balanced translocation and mouse gene inactivation implicate Basonuclin 2 in distal urethral development. Eur J Hum Genet 19: 540-546, 2011.

25. Miller JR: Some epidemiological aspects of teratogen detection. Mutat Res 33: 45-54, 1975.

26. Parker A, Newell KW, Torfs M and Israel E: Appropriate tools for health care: developing a technology for primary health care and rural development. WHO Chron 31: 131-137, 1977.

27. Czeizel A, Toth J and Czvenits E: Increased birth prevalence of isolated hypospadias in Hungary. Acta Paediatr Hung 27: 329-337, 1985.

28. Matlai $\mathrm{P}$ and Beral V: Trends in congenital malformations of external genitalia. Lancet 325: 108, 1985.

29. Baskin LS, Himes K and Colborn T: Hypospadias and endocrine disruption: is there a connection? Environ Health Perspect 109: 1175,2001

30. Wang MH and Baskin LS: Endocrine: disruptors, genital development, and hypospadias. J Androl 29: 499-505, 2008.

31. Dalsenter P, Santana G, Grande S, Andrade AJ and Araujo S: Phthalate affect the reproductive function and sexual behavior of male Wistar rats. Hum Exp Toxicol 25: 297-303, 2006.

32. Nachtigal MW, Hirokawa Y, Enyeart-VanHouten DL, Flanagan JN, Hammer GD and Ingraham HA: Wilms' tumor 1 and Dax-1 modulate the orphan nuclear receptor SF-1 in sex-specific gene expression. Cell 93: 445-454, 1998.

33. Hanley NA, Ball SG, Clement-Jones M, et al: Expression of steroidogenic factor 1 and Wilms' tumour 1 during early human gonadal development and sex determination. Mech Dev 87: 175-180, 1999.

34. Wu SM, Leschek EW, Rennert OM and Chan WY: Luteinizing hormone receptor mutations in disorders of sexual development and cancer. Fetal Pediatr Pathol 19: 21-40, 2000.

35. Geissler WM, Davis DL, Wu L, et al: Male pseudohermaphroditism caused by mutations of testicular $17 \beta$-hydroxysteroid dehydrogenase 3. Nat Genet 7: 34-39, 1994.

36. Rosler A: Steroid 17 $\beta$-hydroxysteroid dehydrogenase deficiency in man: an inherited form of male pseudohermaphroditism. J Steroid Biochem Mol Biol 43: 989-1002, 1992.

37. Parsons JK, Carter HB, Platz EA, Wright EJ, Landis P and Metter EJ: Serum testosterone and the risk of prostate cancer: potential implications for testosterone therapy. Cancer Epidemiol Biomarkers Prev 14: 2257-2260, 2005.

38. Schatzl G, Madersbacher S, Thurridl T, Waldmueller J, Kramer G, Haitel A and Marberger M: High-grade prostate cancer is associated with low serum testosterone levels. Prostate 47: 52-58, 2001.

39. Choi JH, Kim GH, Seo EJ, Kim KS, Kim SH and Yoo HW: Molecular analysis of the AR and SRD5A2 genes in patients with 46, XY disorders of sex development. J Pediatr Endocrinol Metab 21: 545-553, 2008. 